\title{
NEUROSURGICAL PROCEDURES IN PREGNANCY ${ }^{1}$
}

\author{
Bayram Cirak ${ }^{2}$ \\ Nejmi Kiymaz ${ }^{3}$ \\ Memduh Kerman ${ }^{4}$ \\ KadirTahta ${ }^{5}$
}

\begin{abstract}
Cirak B, Kiymaz N, Kerman M, Tahta K. Neurosurgical procedures in pregnancy. Acta Cir Bras
\end{abstract} [serial online] 2003 Jan-Feb;18(1). Available from URL: http://www.scielo.br/acb.

ABSTRACT - Purpose: Over the past few decades maternal mortality has progressively declined because of improved management of the major obstetric problems of hemorrhage, infection, and toxemia. As a result, the relative incidence of deaths resulting from non obstetric causes has increased. Chief among nonobstetric causes are neurologic disorders. Those most common during pregnancy are low back pain, intracranial tumors, subarachnoid hemorrhage, and neurotrauma. The management of the neurosurgical pathologies during pregnancy needs some specifications for both the mother and the fetus. Methods: We performed a retrospective study evaluating the clinical, radiological, and surgical characteristics of 9 patients who have cranial neuropathologies and have undergone neurosurgical intervention. Results: Most of the patients in this study had vaginal delivery. Prominent neurosurgical disease related to cerebral damage. Every patient underwent a laboratory and radiological evaluation. All except one survived the neurosurgical pathology. Neither baby nor mother had significant problem during delivery and neurosurgical intervention. Conclusion: Pregnant women may face to every kind of neurosurgical pathology that nonpregnant women have faced. In addition, pregnancy itself, gives rise some metabolic changes in the women and those changes may cause some neurologic pathologies to be symptomatic or to aggravate the present symptomatology. Because of those reasons, close neurologic follow up of a pregnant woman is of vital importance. At the end of a pregnancy having experienced some neurologic interventions including diagnostic evaluation or surgical intervention does not necessitates the cesarean section for a neurologically intact infant and mother.

KEY WORDS - Neurosurgery. Pregnancy. Anesthesia.

\section{INTRODUCTION}

Recently maternal mortality depending on the obstetric causes declined but in contrast, there is a relative increase in the maternal mortality and morbidity rate due to nonobstetric causes. Neurologic pathologies are among the leading causes of these nonobstetric ones.
The most common neurologic problems encountered during pregnancy are: low back pain, cerebrovascular accidents including subarachnoid hemorrhage due to aneurysms or arteriovenous malformations, intracranial tumors and neurotrauma. During pregnancy the plasma volume increases and cardiac output increases. These changes depend on increased production of estrogen

1. Department of Neurosurgery, Johns Hopkins Hospital Baltimore USA, Yuzuncu Yil University School of Medicine Van Turkiye, Suleyman Demirel University School of Medicine Isparta Turkiye, Pamukkale University School of Medicine Denizli Turkiye

2. MD. Asist. Prof. Department of Neurosurgery, Johns Hopkins Hospital Baltimore USA.

3. MD. Asist. Prof. Department of Neurosurgery, Yuzuncu Yil University School of Medicine Van Turkiye.

4. MD. Asist. Prof. Department of Neurosurgery, Suleyman Demirel University School of Medicine Isparta Turkiye.

5. MD. Prof. Department of Neurosurgery, Pamukkale University School of Medicine Denizli Turkiye. 
and progesterone by the thropoblast in anticipation of the fetal needs ${ }^{1}$. Subarachnoid hemorrhage has been reported to occur in 5 to $12 \%$ of maternal deaths ${ }^{2}$. Primary and metastatic tumors of the central nervous system has been reported to occur less in childbearing ages, but their course may be aggravated by pregnancy and surgery may be necessary for delivery of a viable infant. In the English literature neurosurgical handling of pregnant patients has not been evaluated very well. Some case reports and reviews in French have been published and most of them are in the Obstetric and Gynecology Journals ${ }^{3-7}$.

\section{METHODS}

Nine women admitted and operated on in our Neurosurgery Clinic with the diagnosis of different neurosurgical pathologies during their pregnancy period in between the years of 1992 and 2001 Their files have been evaluated retrospectively for the ages, the time of gestation, signs and symptoms specific to neurosurgical pathologies, diagnostic tools, treatment modality and the outcome of the baby and the mother. Outcomes were evaluated at the time of discharge. If both the baby and the mother have had no neurologic findings it was accepted as good outcome.

In between 1992 and 2001 nine patients were admitted with neurosurgical problems during the course of their pregnancies. None of the patients had any neurologic complaint before pregnancy. Three patients have had diagnosis of subarachnoid hemorrhage. One, due to arteriovenous malformation, two due to aneurysm. One patient diagnosed as intracerebral hemorrhage secondary to a hypertensive attack. Two patients were diagnosed as pituitary apoplexy and another patient was diagnosed as lymphocytic hypophysitis. Two patients admitted with the diagnosis of cerebral contusion caused by traffic accident. One of them gave a healthy baby in the emergency room through vaginal delivery. Mother was treated conservatively. Other one underwent cesarean section. All patients except trauma patients, underwent surgical intervention under general anesthesia. Induction was performed via propofol and maintanance was performed via isofluorane. Following intravenous induction fentanyl was injected to all patients. Data about the patients is summarized in table 1 .

TABLE 1 - Clinical properties of the patients ( CT: computer tomography, MR: Magnetic resonance, MRA, Magnetic resonance angiography, SAH: subarachnoid hemorrhage, C/S: cesarean section, AcoAA: Anterior communicating artery aneurysm, ICH: Intracerebral hemorrhage, ER: Emergency room).

Age Gestation Sign-Symptom Radiology Diagnosis Treatment Delivery type Outcome

\begin{tabular}{l|l|l|l|l|l|l|l}
\hline 22 & 38 & unconcioussness & CT & SAH,AVM & Excision & C/S & Maternal ex \\
\hline 26 & 30 & headache & MR-MRA & Sah,AcoAA & Surgical clipping & Vaginal at term & Good \\
\hline 30 & 28 & Visual disturbance & CT-MR & $\begin{array}{l}\text { Pituitary } \\
\text { apoplexy }\end{array}$ & Surgical excision & Vaginal at term & Good \\
\hline 25 & 38 & unconcioussness & CT & Trauma & conservative & C/S & Maternal excites \\
\hline 33 & 39 & unconcioussness & CT & Trauma & Conservative & Vaginal in ER & Good \\
\hline 29 & 32 & Headache-neck stiffness & CT-Anjio & AcoAA & Surgical clipping & C/S & Good \\
\hline 40 & 33 & Visual disturbance & MR & $\begin{array}{l}\text { Pituitary } \\
\text { apoplexy }\end{array}$ & Surgical excision & Vaginal at term & Good \\
\hline 35 & 36 & Visual disturbance & MR & $\begin{array}{l}\text { Lymphocytic } \\
\text { hypophysitis }\end{array}$ & Surgical excision & Vaginal at term & $\begin{array}{l}\text { Visual } \\
\text { disturbance }\end{array}$ \\
\hline 28 & 37 & Hemiparesia & CT; Angio,MR & ICH & Conservative & C/S & Maternal paresia \\
\hline
\end{tabular}

\section{RESULTS}

Most of the patients in this study had vaginal delivery. Prominent neurosurgical disease related to cerebral damage. Every patient underwent a laboratory and radiological evaluation. All except one survived the neurosurgical pathology. Neither baby nor mother had significant problem during delivery and neurosurgical intervention.

\section{DISCUSSION}

Although neurosurgical problems such as tumors, vascular pathologies, and spinal disorders have been evaluated widely in the literature, those problems occurring in the pregnant women have been poorly discussed. To date in the literature primarily vascular pathologies have been focused to discuss and they are mostly in the Obstetrics and Gynecology or Anesthesio- 
logy Journals Neurosurgical aspects of the pathologies were discussed less ${ }^{6-11} .5-10 \%$ of the maternal deaths are accused of to occur due to the intracranial vascular pathologies ${ }^{2}$. But in the pregnant women not only vascular pathologies took place but some other neurosurgical problems such as, pituitary adenoma, spinal pathologies as like herniated discs, intracranial tumors, trauma and peripheral nerve diseases may also occur $^{3-5,12}$. In a pregnant woman some physiologic and metabolic changes take place from the beginning of the conception to the delivery. Some of which are blood pressure and volume changes, body weight, posture and gait changes. During pregnancy the plasma volume increases from $6^{\text {th }}$ week to reach a maximum of approximately $3600 \mathrm{ml}$ by the $32-34^{\text {th }}$ weeks. The cardiac output increases by $20 \%$ during the first trimester and remains same till the term. Those changes are mostly caused by a raise in estrogen and progesterone hormones during the period of pregnancy ${ }^{1}$. Those physiologic and anatomic changes such as weight gain, posture and gait changes causes either development of new neurosurgical pathologies or aggravation of the symptoms and signs of the present illnesses in a pregnant woman. Eventhough some authors have mentioned that there was no difference between the hemorrhage rates of vascular intracranial pathologies in the pregnant and nonpregnant women ${ }^{13}$, some neurological pathologies may start or may cause signs and symptoms in period of pregnancy $y^{1,11,14,15}$. Some previous literature reported that the incidence of saccular aneurysm have increased during the $30^{\text {th }}$ to $40^{\text {th }}$ gestational week, whereas the incidence of AVM rupture increases during the second trimester shortly before labor, during delivery, and in the early puerperium ${ }^{16}$. Physiologic factors that may contribute to rupture during gestation include the cardiovascular stresses of increased cardiac output and increased blood volume and hormonal changes that affect the connective tissue integrity of vessel walls ${ }^{17}$. Sharsar et al. reported that cerebral hemorrhage risk may increase in the pregnancy and eclampsia is the main cause of both hemorrhagic and nonhemorrhagic stroke and cerebral hemorrhage ${ }^{15}$. They also stated that eclampsia associated intraparenchymal hemorrhage carries a poor prognosis. Some pituitary adenomas, craniopharyngiomas and lymphocytic hypophysitis cases were also reported to occur or increase in size during the pregnancy ${ }^{4-11}$

As Lin et al. and Kasarkis et al. reported some occult lesions may cause problems during the course of pregnancy ${ }^{14,18}$. Pregnancy may cause a pretreated neurosurgical problem to aggravate and a new intervention may be needed ${ }^{9}, 12$. In recent years some reports have been published about the hormone receptors on intracranial tumors especially the meningiomas. Pregnancy may give rise to diagnosis of meningioma through the hormonal changes as described by Goldberg and Rappaport ${ }^{19}$.

The main aim of a neurosurgical intervention in a pregnant woman is to preserve the viability of both the mother and the infant. To maintain this aim some precautions must be performed preoperatively. Preoperative and postoperative care of the pregnant woman is not too much different than that of nonpregnant patients and has been widely discussed in the literature. Operative management and anaesthetic specifications of the pregnant patients carries some important aspects. Each pregnant woman should be considered as full stomach regardless fasting period. There is no evidence of teratogenesis of anaesthetic agents except for nitrous oxide which should be avoided during first and second trimester ${ }^{5,20}$.

The particular hazards of anesthesia during pregnancy stem from physiologic changes in the mother and potential adverse effects on the fetus. Hormonal secretions from the corpus luteum and the placenta, and the mechanical effects of the gravid uterus induce major changes in practically every organ system. In a neurosurgical procedure performed on a pregnant woman some specific precautions must be taken to avoid of fetal asphyxia, to avoid teratogenic drugs and to prevent preterm labor. Fetal oxygenation depends on maternal arterial oxygen content and placental blood flow. Although hypotension and hypocarbia are commonly induced during neurosurgery, those techniques may place fetus at risk for intrauterine asphyxia. This can be avoided by maintaining normal maternal $\mathrm{PaO}^{2}, \mathrm{PaCO}^{2}$, and uterine blood flow. The hypoxia that commonly occurs during anesthesia presents no risk to the fetus. Each organ and system during gestation undergoes a critical stage of differentiation during which vulnerability to teratogenesis greatest and specific malformations may occur. In humans the first trimester appears to be the most vulnerable period. Almost all commonly used anaesthetic drugs are known to be teratogenic in some animal species. Hyperbaric oxygenation, hypoxia, and hypercarbia may also be teratogenic in animals. In women anaesthetized for surgery during pregnancy no specific drug was found safer than another and no specific agent was found to be teratogenic. Although the influence of anesthetics on preterm labor is unknown, the likelihood that anesthetics may stimulate preterm labor during a neurosurgical procedure is small. Nevertheless the patients should be monitored intraoperatively and early postoperatively (at least 2448 hours) for uterine tone, such as adrenergic 
vasopressors, should be avoided, as should the rapid intravenous administration of anticholinesterase drugs 2,5,7,10,20-23. During neurosurgery, osmotic diuresis, controlled hypotension, hypothermia, and hypocarbia are commonly induced to decline the intracranial pressure (ICP). In the pregnant patients, those may adversely affect the fetus. Temporaray clipping of a vessel may be preferred to reduce intraaneurysmal pressure instead of hypotension. In addition to the monitors used during neurosurgical interventions monitorization of the fetus and uterus should be used if possible. An external Doppler fetal heart rate monitor will be useful. Close observation of maternal blood pressure and promt treatment of hypotension and hypoxia are essential for a well fetus ${ }^{2,7,20}$. Postoperative management of pregnant patients after a neurosurgical intervention is not so much different than that of nonpregnant. Extubation should be delayed until the patient is sufficiently awake to protect her airway from regurgitation and aspiration. The patient should be placed in a lateral postion with her head slightly elevated. Fetal heart rate and uterine tone should be monitored at least 24-48 hours.

During delivery of a woman who have an intracranial mass lesion or vascular lesion, prevention of hypertension and increased ICP is crucial. Except 4 of our patients all delivered babies at term through vaginal route and had no problem. Those patients who deliver through cesarean section were as follows: One of them was a SAH due to AVM, the other one was SAH anterior communicating artery aneurysm and the third one was a neurotrauma patient. The last one was intracerebral hemorrhage.

Vaginal delivery is acceptable for patients with increased intracranial pressure. But, the second stage of labor must be shortened and maternal straining with the valsalva maneuver avoided because it raises ICP. To shorten the second stage of labor and maternal straining administration of segmental lumbar epidural or caudal anesthesia and the use of outlet forceps are recommended. When cesarean delivery is required, epidural anesthesia is recommended. Although electice cesarean delivery has been recommended for patients with unruptured AVMs, most authors advocate this procedure only for accepted obstetric and fetal indications. For patients with documented aneurysm or AVM, intracranial tumor cesarean delivery provides no definitive advantage over vaginal delivery in protecting from increased ICP. In some cases if labor supervenes after $\mathrm{SAH}$, a procedure combining cesarean section and neurosurgery may be used ${ }^{2,10}$.

Different neurosurgical pathologies may be observed in pregnancy. Since the pregnancy alters the metabolic and physiologic status of the women some pretreated pathologies may aggravate or new pathologies are not different in the pregnant women than that of nonpregnant, therapeutic interventions, anaesthetic medication, and follow up must aimed to have a well baby and mother. Also, having experienced a neurosurgical intervention in their pregnancy period does not necessitates the delivery to be cesarean section.

\section{CONCLUSION}

Pregnant women may face to every kind of neurosurgical pathology that nonpregnant women have faced. In addition, pregnancy itself, gives rise some metabolic changes in the women and those changes may cause some neurologic pathologies to be symptomatic or to aggravate the present symptomatology. Because of those reasons, close neurologic follow up of a pregnant woman is of vital importance. At the end of a pregnancy having experienced some neurologic interventions including diagnostic evaluation or surgical intervention does not necessitates the cesarean section for a neurologically intact infant and mother.

\section{REFERENCES}

1. Naidoo K, Bhigjee Al. Multiple cerebellar haemangioblastomas symptomatic during pregnancy. Br J Neurosurg 1998;12:281-5.

2. Rosen MA. Anesthesia for neurosurgery during pregnancy. In: Shnider SM, Levinson G. Anesthesia for obstetrics. Baltimore: Williams and Wilkins; 1993. p. 551-61.

3. Magyar DM, Marshall JR. Pituitary tumors and pregnancy. Am J Obstet Gynecol 1978;132:739-51.

4. Maniker AH, Krieger AJ. Rapid recurrence of craniopharyngioma during pregnancy with recovery of vision: a case report. Surg Neurol 1996;45:324-7.

5. Molins GN, Gargallo LMC, Castells AMV, Rubival AM, Segovia VD. Anesthesia for brain tumor surgery during pregnancy: presentation of a case. Rev Esp Anestesiol Reanim 1990;37:291-3.

6. Soutoul JH, Gouaze A, Gallier J, Santini JJ. Neurosurgery and pregnancy. Rev Fr Gynecol Obstet 1971;66:603-18.

7. Soutoul JH, Galler J, Gouaze A, Santini JJ. Neurosurgery in pregnancy: problems raised by exploratiosns, medical treatments, anesthesia and resuscitation. J Gynecol Obstet Boil Reprod 1972;1:33-46

8. Cannell DE, Botterell EH. Subarachnoid hemorrhage and pregnancy. Am J Obstet Gynecol 1956;72:844-55.

9. Cast MJ, Grubb RL, Strickler RC. Maternal hydrocephalus and pregnancy. Obstet Gynecol 1983;62:29-31.

10. D'Haese J, Christiaensens F, D'Haens J, Camu F. Combined cesarean section and clipping of a ruptured cerebral aneurysm: a case report. J Neurosurg Anesthesiol 1997;9:341-5.

11. Feigenbaum SL, Martin MC, Wilson CB, Jaffe RB. Lymphocytic adenohypophysitis: a pituitary mass lesion occurring in the pregnancy: proposal for medical treatment. Am J Obstet Gynecol 1991;164:1549-55.

12. Cusimano MD, Meffe FM, Gentili F, Sermer M. Ventriculoperitoneal shunt malfunction during pregnancy. Neurosurgery 1990;27:969-71. 
13. Fujita K, Tsunoda H, Shigemitsu S, Kubo T. Clinical study on the intracranial arteriovenous malformation associated with pregnancy. Nippo sanka Fujinka Zasshi 1995;47:1359-65.

14. Kasarkis EJ, Tibbs PA, Lee C. Cerebellar hemangioblastoma symptomatic during pregnancy. Neurosurgery 1988; $22: 770-2$.

15. Sharsar T, Lamy C, Mas JL. Incidence and causes of strokes associated with pregnancy and puerperium: a study in public hospitals of le De France. Stroke in pregnancy study group. Stroke 1995;26:930-6.

16. Rish BL. Treatment of intracranial aneurysms associated with other entities. South Med J 1978;71:553-7.

17. Dias MS, Sekhar LN. Intracranial hemorrhage from aneurysms and arteriovenous malformations during pregnancy and puerperium. Neurosurgery 1990;27:855-66.

18. Lin TK, Chang CN, Wai YY. Spontaneous intracerebral hematoma from occult carotid-cavernous fistula during pregnancy and puerperium: case report. J Neurosurg 1992;76:714-7.

19. Goldberg M, Rappaport ZH. Neurosurgical, obstetric and endocrine aspects of meningioma during pregnancy. Isr J Med Sci $1987 ; 23: 825-8$

20. Wilson F, Sedzimir CB. Hypothermia and hypotension during cranioyomy in a pregnant woman. Lancet 1959;2:947-9.

21. Matsuki A, Oyama T. Operation under hypothermia in pregnant woman with an intracranial arteriovenous malformation. Can Anaesth Soc J1972;19:184-91.

22. Pevehouse BC, Boldrey E. Hypothermia and hypotension for intracranial surgery during pregnancy. Am J Surg 1960;100:633-4

23. Solomon RA, Fink ME, Lennihan L. Early aneurysm surgery and prophylactic hypervolemic hypertensive therapy for the treatment of aneurismal subarachnoid hemorrhage. Neurosurgery 1988;23:699-704.

Cirak B, Kiymaz N, Kerman M, Tahta K. Procedimentos neurocirúrgicos na gravidez. Acta Cir Bras [serial online] 2003 Jan-Fev;18(1). Disponível em URL: http://www.scielo.com.br.

RESUMO - Objetivo: Nas últimas décadas a mortalidade maternal tem declinado progressivamente devido ao melhor controle dos grandes problemas obstétricos tais como a hemorragia, infecção e toxemia. Em contrapartida a incidência de óbitos resultantes de causas não obstétricas tem aumentado, sobretudo as resultantes de doenças neurológicas. As causas mais comuns, durante a gravidez, são tumores intracraneanos, hemorragia subaracnóidea e trauma neurológico. O controle de doenças neurocirúrgicas durante a gravidez necessita de cuidados especiais para a mãe e o feto. Métodos: Realizou-se estudo retrospectivo avaliando as características clínicas, radiológicas e cirúrgicas de nove pacientes que tiveram doenças que exigiram intervenção neurocirúrgica. Resultados: $\mathrm{Na}$ maioria das pacientes ocorreu parto vaginal. Cada paciente foi submetida a avaliação laboratorial e radiológica. Todas sobreviveram com exceção de uma. Não houve maiores complicações para a mãe e o feto, seja durante o procedimento cirúrgico seja durante o parto. Conclusão:

Pacientes grávidas com doenças neurológicas e que se submeteram a procedimentos operatórios podem não necessitar de cesareanas.

DESCRITORES - Neurocirurgia. Gravidez. Anestesia.

Conflict of interest: none

Financial source: none

Address for correspondence:

Bayram Cirak MD

103 Willow Bend Dr. Apt. 4-D

Owings Mills, MD, 21117, USA

Phone: (443) 3947149

bayramcirak@yahoo.com

Data do recebimento: 18/09/2002

Data da revisão: 17/10/2002

Data da aprovação: 12/11/2002 